\title{
ANALISIS KUALITAS LAYANAN, KEMAMPUAN DAN KINERJA PENGURUS POKJAR TERHADAP KEPUASAN MAHASISWA DI UPBJJ-UT PALANGKA RAYA
}

\section{An Analysis of Service Quality, Competence and Performance of Pokjar Administrators in Relation to Student Satisfaction at UPBJJ-UT of Palangka Raya}

\author{
Rahmaddian, S.E., M.M.'* \\ Stefani Made Ayu A.K., S.Sn., \\ M.Si ${ }^{2}$ \\ Deni Surapto, S.E., M.Si ${ }^{3}$ \\ *IUniversitas Terbuka, Palangka Raya, \\ Kalimantan Tengah, Indonesia \\ 2 Universitas Terbuka, Palangka Raya, \\ Kalimantan Tengah, Indonesia \\ 3 Universitas Terbuka, Pondok Cabe, \\ Tangerang, Indonesia \\ *email: \\ rahmadian@ecampus.ut.ac.id \\ stefanimadeayu@ecampus.ut.ac.id \\ denis@ecampus.ut.ac.id
}

Kata Kunci:

Kualitas layanan

SEM PLS

Kinerja

SDM

Keywords:

Service Quality

SEM PLS

Performance

Human Resources

\begin{abstract}
Abstrak
Universitas Terbuka Palangka Raya (UPBJJ-UT Palangka Raya) menjangkau mahasiswa yang memerlukan pendidikan tinggi melalui mitra pengurusan di Kabupaten yang bernama pengurus pokjar (kelompok belajar). Karena letak dan cakupan wilayah yang luas UPBJJ-UT Palangka Raya memiliki sebaran mahasiswa sangat heterogen. Layanan yang diberikan pengurus pokjar menjadi sangat penting dalam mengoptimalkan kualitas layanan Universitas Terbuka kepada mahasiswa yang tidak dapat selalu bertemu dengan mahasiswa yang tersebar di pelosok Kalimantan Tengah. Kinerja layanan pengurus pokjar yang sangat kompleks membuat mahasiswa memiliki kesan dan asosiasi negatif terhadap pelayanan yang telah diberikan. Tantangan yang dihadapi oleh pengurus pokjar diharapkan mampu mengembangkan organisasi secara efektif, efesien, akuntabel, responsif serta transparan. Penelitian ini ingin melihat bagaimana kualitas layanan, kompetensi, kinerja serta tanggapan mahasiswa terhadap pelayanan pengurus pokjar di UPBJJ-UT Palangka Raya melalui metode SEM PLS. Hasil penelitian ini menunjukkan bahwa kualitas layanan pengusur pokjar baik, kompetensi yang memenuhi dan kinerja layanan baik; serta mahasiswa puas terhadap layanan pengurus pokjar.
\end{abstract}

\begin{abstract}
Open University of Palangka Raya (UPBJJ-UT of Palangka Raya) has acknowledged the education-attainment gap between rural and urban areas, and officials have determined ways to connect with students in the far corners of Central Kalimantan. UPBJJ-UT of Palangka Raya has set up study groups (PokJar) through which non urban students acquire university education. Due to its wide range of locations and heterogeneous student populations, PokJar is established through management partnership that constitutes a governing body that oversees the district-wide operation and the delivery of the continuing education programs. On this optimistic basis, the service provided by PokJar administrators becomes central to optimizing quality education in a learning environment where the administrators and students are physically separated. However, the complexity of PokJar service and administrator performance may link to negative perceptions among students. Recognizing the nature of challenges facing PokJar management is expected to usher in the planning of improvement crucial to organizational development that is effective, efficient, accountable, responsive and transparent. This study taps into the quality service, the competence and performance of PokJar administrators of UPBJJ-UT of Palangka Raya in terms of student-perceived values using PLS-SEM method. The overall results address favorable responses, strongly suggesting a good measure of how PokJar administrators' service, competence and performance meet student expectation.
\end{abstract}

(ब) $\odot \odot$

(C) year The Authors. Published by Institute for Research and Community Services Universitas Muhammadiyah Palangkaraya. This is Open Access article under the CC-BY-SA License (http://creativecommons.org/licenses/bysa/4.0/). DOI: https://doi.org//0.33084/anterior.vxix.xxx.

\section{PENDAHULUAN}

Universitas Terbuka (UT) memiliki karakteristik sistem pendidikan jarak jauh. Sistem ini menuntut mahasiswanya untuk mandiri dan proaktif dalam menempuh studi. Mahasiswa UT harus memiliki kedisiplinan untuk mengatur waktu belajar, membuat prioritas, mempelajari bahan ajar, mengatasi permasalahan dan kesulitan belajar secara cepat dan mandiri. Namun demikian, kesenjangan akses, teknologi, dan pengetahuan di daerah terpencil yang 
harus menjadi jangkauan UT menjadi tantangan tersendiri dalam memberikan layanan kepada mahasiswa.

UT memiliki unit pelaksana pembelajaran jarak jauh di Kalimantan Tengah, dikenal dengan UPBJJ-UT Palangka Raya. Dengan cangkupan geografis provinsi Kalimantan Tengah yang sangat luas, UPBJJ-UT Palangka Raya memiliki total 538I mahasiswa program S-I yang tersebar di 13 Kabupaten dan I Kota. Jumlah mahasiswa yang cukup banyak menuntut perhatian dan pelayanan yang cepat serta optimal sangat bertolak belakang dengan jumlah pegawai UPBJJ-UT Palangka Raya yang hanya berjumlah 16 orang ASN. Keberadaan pengurus kelompok belajar (pokjar) menjadi perpanjangan tangan dari UPBJJ-UT Palangka Raya dalam memberikan layanan kepada mahasiswa yang berada di luar kota Palangka Raya.

Menurut Pedoman Pengurus Pokjar (UT, 20I8), Pokjar adalah kumpulan mahasiswa UT yang membangun komitmen dan kesepakatan bersama untuk saling membantu dan saling mendukung kelancaran dan keberhasilan belajar di UT dengan atau tanpa fasilitas pihak lain. Pokjar dapat berbentuk Pokjar Mandiri atau Pokjar UPBJJ-UT. Pokjar Mandiri adalah Pokjar yang dibentuk atas inisiatif mahasiswa secara mandiri dan diketuai oleh mahasiswa. Pokjar UPBJJ-UT dibentuk oleh UPBJJ-UT untuk membantu memberikan layanan kepada sekelompok mahasiswa dan dikoordinasikan oleh satu orang Pengurus Pokjar. Dengan keberadaan pengurus pokjar, UPBJJ-UT terbantu dalam kegiatan sosialisasi promosi, rekruitmen, registrasi, OSMB Distribusi bahan ajar, bantuan belajar, kemahsiswaan, informasi lokasi ujian, UPI dan kegiatan UT lainnya. Pengurus pokjar diharapkan dapat memberikan sekaligus menjaga keberlangsungan citra positif UT, berkontribusi memberikan informasi potensi calon mahasiswa, memberikan sosialisasi dan promosi tentang program-program pendidikan UT, menyebarluaskan informasi yang relevan kepada mahasiswa, serta membangun komunikasi, interaksi dan kerjasama yang positif antara UPBJJ-UT, mahasiswa, tutor, supervisor, mitra dan pengurus pokjar lain dalam penyelenggaraan kegiatan pembelajaran jarak jauh UT.

Parasuraman et al. (Tjiptono, 2005) telah melakukan pengembangan suatu alat ukur kualitas layanan yang disebut SERVQUAL (Service Quality). Hasil penelitian tersebut menunjukkan bahwa dimensi dan atribut model SERVQUAL yang digunakan untuk pengukuran kualitas adalah dimensi keandalan, daya tanggap, kenyamanan/jaminan, empati, dan bukti fisik. Menurut Parasuraman et al. (Rangkuti, 2003) ciri-ciri kualitas layanan jasa dapat dievaluasi dalam lima dimensi, yaitu: reliability, responsiveness, assurance, emphaty, dan tangible.

Penelitian sebelumnya oleh Susila (2010) mengungkapkan bahwa daya tanggap, bukti fisik, kredibilitas dan empati berpengaruh positif dan signifikan terhadap kepuasan masyarakat. Kualitas layanan mempengaruhi kepuasan pelanggan dan loyalitas juga memiliki pengaruh kuat pada perilaku pelanggan. Karena kualitas layanan adalah salah satu pendahulunya dari kepuasan pelanggan dan ada banyak kualitas pelayanan yang berhubungan di antaranya adalah kepuasan, kesetiaan, persepsi nilai, niat dan perilaku pelanggan (Yarimoglu, 20I5). Kemampuan bertindak untuk memberikan pelayanan merupakan kegiatan yang senyatanya melakukan suatu tindakan yang responsif terhadap para peminta layanan.

Berangkat dari tantangan dan kebutuhan atas pelayanan yang baik kepada mahasiswa UPBJJ-UT Palangka Raya, peneliti ingin menganalisis bagaimana kualitas layanan, kompetensi, kinerja dan kepuasan mahasiswa terhadap layanan pengurus pokjar di UPBJJ-UT Palangka Raya dengan menerapkan model yang ideal dengan metode SEM PLS. Penelitian ini bertujuan untuk mengetahui bagaimana kualitas layanan, kompetensi, kinerja dan kepuasan mahasiswa terhadap layanan pengurus pokjar 
sehingga menghasilkan inovasi model layanan pengurus pokjar UPBJJ-UT Palangka Raya.

Sebagai kajian literatur, penelitian ini mengambil konsep kepuasan yaitu evaluasi terhadap apa yang diharapkan dengan kenyataan (kinerja) yang dirasakan masyarakat terhadap pelayanan yang telah diberikan oleh aparatur. Indikator yang digunakan dalam mengukur kepuasan layanan adalah: a) kepuasan masyarakat atas pengetahuan, kemampuan, kesopanan dan dapat dipercaya dari aparat, b) kepuasan masyarakat atas pemberian info yang baik dan jelas oleh aparat, c) kepuasan masyarakat untuk pelayanan yang cepat dan akurat oleh aparat, d) kepuasan masyarakat atas perhatian dan kepedulian aparat.

Definisi kualitas pelayanan (service quality) berpusat pada upaya pemenuhan kebutuhan dan keinginan pelanggan serta ketetapan penyampaiannya untuk mengimbangi harapan pelanggan. Menurut Wyckof (Lovelock, 1988) kualitas jasa adalah tingkat keunggulan yang diharapkan dan pengendalian atas tingkat keunggulan tersebut untuk memenuhi keinginan pelanggan. Kualitas harus dimulai dari kebutuhan pelanggan dan berakhir pada persepsi pelanggan (Kotler, 1994). Hal ini berarti bahwa citra kualitas yang baik bukanlah berdasarkan sudut pandang atau persepsi pihak penyedia jasa, melainkan berdasarkan sudut pandang atau persepsi pelanggan. Pelangganlah yang mengkonsumsi kualitas pelayanan. Persepsi pelanggan terhadap kualitas pelayanan merupakan penilaian menyeluruh atas keunggulan suatu pelayanan.

Dalam konteks kualitas produk (barang dan jasa) dan kepuasan, telah tercapai konsensus bahwa harapan pelanggan memiliki peranan yang besar sebagai standar perbandingan dalam evaluasi kualitas maupun kepuasan. Menurut Olson dan Dover (Zeithaml et al., 1993), harapan pelanggan merupakan keyakinan pelanggan sebelum mencoba atau membeli suatu produk, yang dijadikan standar atau acuan dalam menilai kinerja produk tersebut. Kualitas pelayanan sering didefinisikan sebagai perbandingan antara harapan dan kinerja aktual pelayanan jasa (Zeithaml et al., 1988). Dalam level operasional, riset kualitas pelayanan didominasi oleh instrumen SERVQUAL, didasarkan atas model kesenjangan. Kualitas pelayanan merupakan konstruk multi dimensi, yang terdiri dari:

I. Tangibles, adalah dimensi kualitas pelayanan yang meliputi fasilitas fisik, perlengkapan, pegawai dan sarana komunikasi untuk membantu dan memberikan layanan dengan tanggap dan cepat pada masyarakat. Indikator: a) Responsif dengan kondisi kebutuhan masyarakat; b) Pelayanan yang cepat dan akurat.

2. Reliability, didefinisikan sebagai kemampuan untuk memberikan layanan dengan segera yang dapat diandalkan, akurat dan memuaskan. Hal ini menyangkut menepati janji, penanganan keluhan, dan lain-lain.

3. Responsiveness, dapat dideskripsikan sebagai kesediaan untuk membantu dan memberikan pelayanan yang tepat bagi pelanggan. Dimensi ini menekankan sikap penyedia jasa untuk memperhatikan permintaan, pertanyaan dan keluhan pelanggan.

4. Assurance, merupakan dimensi kualitas pelayanan yang memfokuskan pada kemampuan untuk mendapatkan kepercayaan dan keyakinan pelanggan, yang mencakup pengetahuan, kemampuan, kesopanan dan sifat dapat dipercaya yang dimiliki para staf; bebas dari bahaya, resiko atau keragu-raguan.

5. Empathy, merupakan dimensi kualitas pelayanan yang menekankan pada perlakukan pelanggan sebagai personal, yang mencakup kemudahan dalam melakukan hubungan, komunikasi yang baik, perhatian pribadi dan memahami kebutuhan para pelanggan.

Manfaat utama menggunakan lima dimensi SERVQUAL adalah SERVQUAL terbukti secara empiris digunakan 
dalam berbagai setting penelitian. Walaupun demikian, instrumen SERVQUAL membutuhkan adaptasi, sesuai dengan konteks jasa yang diteliti (Bloemer et al., 1998). Untuk menganalisa kualitas jasa dapat dilakukan dengan mengkuantifikasikan dimensi kualitas dengan menggunakan skala interval pada kuesioner yang disebarkan kepada responden. Dari hasil skala interval ini, maka kualitas pelayanan dapat diukur. Mengukur kualitas pelayanan dengan kualitas pelayanan yang diterima (Zeithaml et al., 1993), merupakan model yang mengukur perbedaan antara harapan dengan persepsi pelanggan. Kepuasan pelanggan akan terpenuhi jika apa yang dirasakan melebihi dari apa yang diharapkan.

Pelayanan (service) adalah kegiatan yang dapat diidentifikasikan dan tidak berwujud dan merupakan tujuan penting dari suatu rencana transaksi, guna memberikan kepuasan kepada konsumen. (Kotler, 2007) mengemukakan bahwa pelayanan adalah setiap kegiatan atau manfaat yang ditawarkan oleh suatu pihak kepada pihak lain dan pada dasarnya tidak berwujud dan tidak pula berakibat kepemilikan sesuatu dan produksinya dapat atau tidak dapat dikaitkan dengan suatu produk fisik. Kualitas pelayanan yang baik merupakan sebuah konsep yang telah diharapkan konsumen sehingga jasa yang diterima atau diharapkan akan mempengaruhi persepsi baik dan memuaskan dan melebihi ekspektasi harapan konsumen (Liao, 20II). Definisi kualitas pelayanan (service quality) berpusat pada upaya pemenuhan kebutuhan dan keinginan pelanggan serta ketetapan penyampaiannya untuk mengimbangi harapan pelanggan. Menurut Wyckof (dalam Lovelock, 1988) kualitas jasa adalah tingkat keunggulan yang diharapkan dan pengendalian atas tingkat keunggulan tersebut untuk memenuhi keinginan pelanggan. Kualitas harus dimulai dari kebutuhan pelanggan dan berakhir pada persepsi pelanggan (Kotler, 1994). Hal ini berarti bahwa citra kualitas yang baik bukanlah berdasarkan sudut pandang atau persepsi pihak penyedia jasa, melainkan berdasarkan sudut pandang atau persepsi pelanggan.

Kompetensi adalah suatu karakter superior seseorang yang membuat orang dapat berkinerja dalam pekerjaan. Seseorang dikatakan kompeten bila memiliki keterampilan untuk mengerjakan pekerjaan dengan mudah, cepat, intuitif dan minim/jarang membuat kesalahan. Menurut Boulter et.al (1996) level kompetensi adalah keterampilan, pengetahuan, konsep diri, imajinasi diri, sikap dan motivasi.

Kinerja merupakan hasil keluaran yang dicapai dari perolehan yang telah dilakukan, dikerjakan seseorang dalam melaksanakan kerja atau tugas. Kinerja adalah prestasi kerja, yaitu hasil kerja selama periode tertentu dibanding dengan berbagai kemungkinan. Konsep kinerja adalah perilaku nyata yang ditampilkan setiap orang sebagai prestasi kerja yang dihasilkan oleh karyawan sesuai dengan perannya dalam perusahaan (Rivai, 2005). Arti kinerja merupakan hasil yang dicapai oleh seseorang dalam melaksanakan tugas atau beban tanggung jawab menurut ukuran atau standar tertentu yang berlaku pada masing-masing organisasi (llyas, 2005). Pengukuran kinerja menurut adalah suatu alat manajemen untuk meningkatkan kualitas pengambilan keputusan dan akuntabilitas (Simamora, 2004). Pengukuran kinerja harus mempertimbangkan hal-hal berikut (Dharma, 2004):

a) Kuantitas, yaitu jumlah yang harus diselesaikan harus dicapai.

b) Kualitas, yaitu mutu yang harus dihasilkan (baik atau tidaknya).

c) Ketepatan waktu, yaitu sesuai tidaknya dengan waktu yang direncanakan.

Faktor-faktor yang mempengaruhi kinerja dapat mempengaruhi kinerja dari pegawai di dalam suatu organisasi atau perusahaan (Mangkunegara, 2005) :

a. Faktor kemampuan (ability)

I. Kemampuan potensi (IQ). 
2. Kemampuan reality (knowledge + skill).

b. Faktor motivasi (motivation)

\section{METODOLOGI}

Populasi dalam penelitian ini adalah seluruh mahasiswa Pokjar UPBJJ-UT Palangka Raya. Teknik sampling dengan proporsional random sampling yaitu pengambilan secara acak proporsional, sebanyak 100 orang. Teknik pengumpulan data dilakukan dengan cara wawancara, observasi dan penyebaran kuisioner.Teknik analisa data yang digunakan yaitu uji validitas dan reliabilitas instrument, regresi linier berganda, uji t, uji F, dan koefisien determinasi.

Hipotesis pada penelitian ini adalah:

$\mathrm{HI}$ : Kualitas layanan mempunyai pengaruh terhadap kepercayaan mahasiswa kepada pengurus pokjar/perwakilan UPBJJ-UT Palangka Raya.

$H 2$ : Kompetensi pengurus pokjar berpengaruh kepada persepsi mahasiswa.

H3: Kinerja pengurus pokjar berpengaruh kepada kepuasan layanan mahasiswa.

H4: Kinerja dan kompetensi Pengurus pokjar berpengaruh terhadap persepsi mahasiswa.

Metode yang digunakan untuk analisis dengan Partial Least Square (PLS) dan analisis deskriptif. Statistik deskriptif dapat membantu statistik untuk mendeskripsikan data-data yang dikumpulkan dalam penelitian ini. Selain itu data dianalisis dengan menggunakan metode Partial Least Square (PLS) dan menggunakan tools SmartPLS.

\section{HASIL DAN PEMBAHASAN}

Terdapat jumlah responden dalam penelitian ini terdiri dari laki-laki sebesar $43 \%$ dan perempuan sebesar $57 \%$. Jumlah responden berdasar usia 20-30 tahun sebanyak $41 \%$, usia $31-40$ tahun sebanyak $30 \%$ dan $29 \%$ usia 4|-50 tahun.

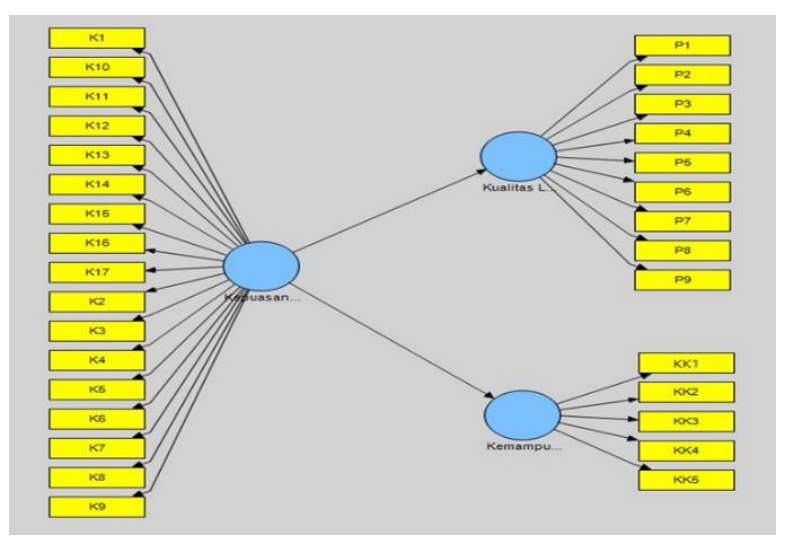

Gambar I. Model Awal SEM

Dari hasil pengolahan didapat model awal secara keseluruhan yang terdiri variabel eksogen adalah dari kepuasan yang terdiri dari 9 komponen indikator sub varibel yang tidak dapat dipengaruhi oleh variabel lainnya. Diikuti oleh varibel endogen lain yang saling berhubungan yaitu variabel kualitas yang terdiri 9 komponen, variabel kemampuan 5 komponen.

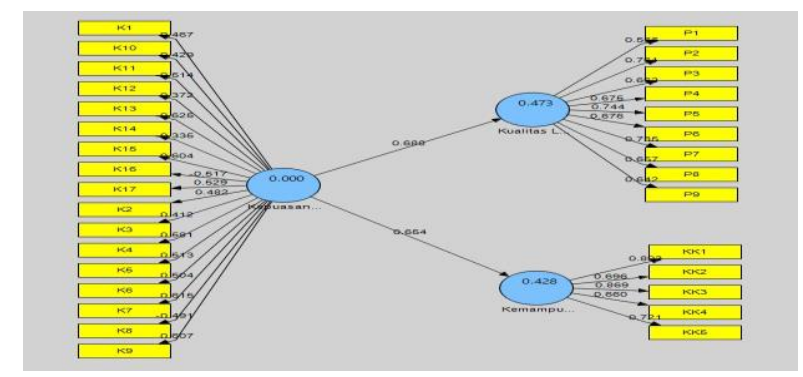

Gambar 2. Outer Model

Setelah langkah awal dilakukan adalah pengujian validitas dari masing-masing outer loading variabel. Suatu outer loading dapat dikatakan baik apabila adalah jika outer loading-nya diatas 0.70 sedangkan ambang batas 0.50 adalah batas tolelir dan dibawah 0,40 akan dikeluarkan dari analisis. Untuk kepuasan atas layanan UT terdapat 2 untuk KI2 sebesar 0.372 dan $\mathrm{K} / 4$ sebesar 0.335 . 


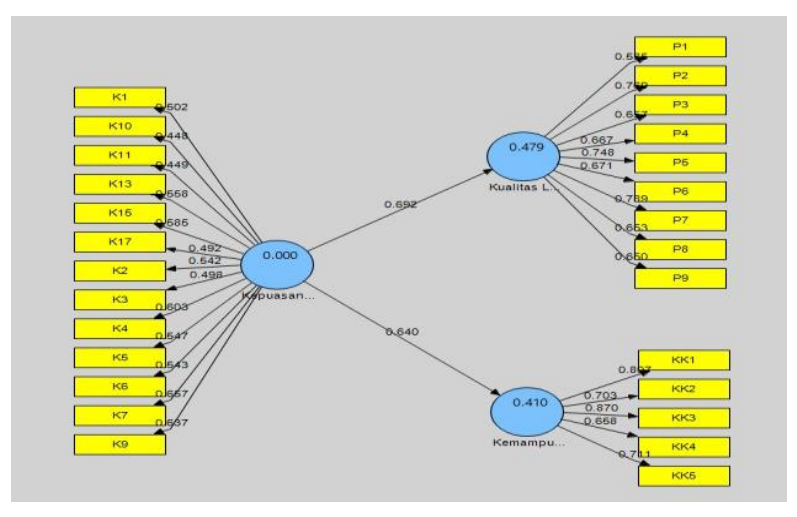

Gambar 3. Outer Model Final

Hasil algorithm final dalam penelitian ini menunjukan bahwa indikator kepuasan mahasiswa beberapa indikator dibuang karena kurang dari 0.4 antara lain: K8 kecepatan dan ketanggapan pengurus dalam memberikan pelayanan, $\mathrm{K} / 2$ adanya kesesuaian antara biaya yang dikeluarkan dengan biaya yang telah ditetapkan, KI4 adanya tambahan biaya dalam pelayanan di luar yang ditetapkan, dan KI6 ada ketidakadilan pengurus dalam memberikan pelayanan).

Discriminant validity digunakan untuk memastikan bahwa setiap konsep dari variabel laten/konstruk berbeda dengan variabel laten lainnya antara lain kepuasan atas layanan yang tertinggi adalah KI5 0.584865 merasakan keamanan dalam menerima pelayanan, tingkat keamanan dan kenyamanan terhadap perlindungan konsumen dalam menerima pelayanan jasa meskipun pelayanan yang diberikan terhadap pengurus pokjar berdasarkan atas asan kepercayaan dan kekeluargaan yang tinggi. Berikutnya adalah KI 0.502139 kemudahan dalam menjangkau kantor pengurus pokjar dengan moda trasportasi. Pengurus pokjar adalah mitra UT dalam kerjasama memberikan layanan akan tetapi pengurus tidak memaksakan pemilihan alternatif dalam pemberian layanannya kepada mahasiswa. Bila mahasiswa ingin menjangkau UPBJJ-UT dapat datang langsung ke kantor UPBJJ-UT Palangka Raya, berikutnya adalah kemampuan kerja pemberi layanan KK3 $(0,871044)$ pengurus bersungguh-sungguh dalam memberikan pelayanan. Rasa sungguh-sungguh dan tanggung jawab pekerjaan/amanah yang diharapkan UPBJJ-UT kepada pengurus pokjar ialah agar dalam memberikan kepuasan layanan bertujuan agar harapan yang diinginkan mahasiswa tersampaikan dengan baik.

Komponen keempat adalah KKI (0.807362) pengurus merasa mampu memberikan informasi pelayanan dengan jelas sesuai prosedur. Peraturan/prosedur, petunjuk kerja dan rekaman kerja yang harus dipahami oleh pengurus pokjar dalam melayani mahasiswa yang tidak dapat menjangkau UPBJJ-UT. Untuk KK2 (702818) mahasiswa merasa pengurus mampu menjawab semua pertanyaan, setiap pertanyaan dan pernyataan pengurus harus mampu berempati kepada pelanggannya agar setiap dapat menjawab kebutuhan pelanggannya. Keinginan konsumen dalam memenuhi harapannya adalah ingin dapat dilayani dengan cepat dan tanggap dalam memenuhi permintaan, ini dapat dibuktikan dalam hasil olah data komponen KK5 (0.7III75) dimana mahasiswa merasa pengurus memberikan pelayanan dengan cepat. Selain cepat pengurus dituntut dalam ketepatan dalam memberikan pelayanannya terutama tenggat waktu atau target yang dapat diselesaikan, hal ini berkenaan dengan kepuasan untuk komponen KK4 (0.657523) merasa pengurus tepat waktu proses dalam memberikan pelayanan.

Untuk variabel kualitas pemberian pelayanan nilai paling besar dicapai oleh indikator P7 (0.789122): konsumen merasakan pengurus bersikap sopan dan ramah dalam memberikan layanan. Hal ini disebabkan karena budaya kesopanan dan rasa santun sangat membenak dalam diri pengurus pokjar di daerah, yaitu dengan rasa kekeluargaan, kekerabatan dan kebersamaan yang membuat erat dalam memberikan layanan. Menjaga pelanggan purna jual sangat penting dengan tujuan agar konsumen merasa selalu diperhatikan dan dipenuhi keinginannya. Untuk itu dibutuhkan komitmen yang tinggi terutama kedisiplinan pengurus pokjar. Nilai komitmen sejalan dengan kepuasan mahasiswa terhadap kedisplinan untuk 
komponen P2 (0.768940) bahwa konsumen merasa pengurus bersikap disiplin dalam memberikan layanan. Rasa disiplin diiringi dengan komitmen dan tanggung jawab moral kepada pekerjaan untuk memberikan layanan terbaik seperti komponen P5 (0.748I89) pengurus bertanggung jawab dalam memberikan pelayanan.

Ketentuan dan batasan pelayanan harus disepakati secara bersama sesuai dengan aturan yang berlaku. Misalnya batas akhir registrasi mahasiswa yang tidak dapat diperpanjang, bukti tersebut tertuang pada komponen P4 (0.6669/3): pengurus merasa bersikap tegas memberikan layanan, Komponen P6 (0.670517) menyebutkan bahwa kemudahan mahasiswa mudah dalam menghubungi pengurus pelayanan. Mobilitas pengurus pokjar yang tinggi membuat terkadang mahasiswa sulit bertemu; namun pendapat ini berbeda dengan hasil olah kuesioner untuk komponen P3 (0.656730) pengurus selalu berada di tempat untuk memberikan layanan. Komponen P8 (0.653170) pengurus mampu memberikan target penyelesaian berbagai keluhan dan layanan yang diminta oleh mahasiswa. Penghargaan tertinggi terhadap layanan kepada konsumen adalah berempati serta berkomitmen untuk dapat melayani sesuai yang diharapkan konsumen meskipun hanya dengan ucapan terima kasih dalam mengakhiri layanan, ini dapat dibuktikan untuk P9 (0.6497/0) mendapat ucapan terima kasih setelah selesai proses layanan ucapan sapaan PI (0.5847/0) oleh pengurus pokjar. Model variabel dan komponen-komponen pendukung diatas adalah Model yang mempunyai discriminant validity yang baik jika setiap nilai loading dari setiap indikator dari sebuah variabel laten memiliki nilai loading yang paling besar dengan nilai loading lain terhadap variabel latennya.

Korelasi maksimal konstrak kepuasan mahasiswa dengan konstrak lainnya adalah 0.640021 , sedangkan nilai akar AVE-nya adalah 0.5468 I8. Korelasi maksimal konstrak kualitas layanan dengan konstrak lainnya adalah 0.635968, sedangkan nilai akar AVE-nya adalah 0.6904I6. Hal ini berarti nilai akar AVE untuk variabel kepuasan mahasiswa dan kualitas layanan memiliki angka diatas korelasi variabel masing-masing sehingga dianggap memiliki discriminant validity. Sedangkan untuk variabel laten kemampuan kerja memiliki nilai akar AVE dibawah nilai korelasi variabel latennya.

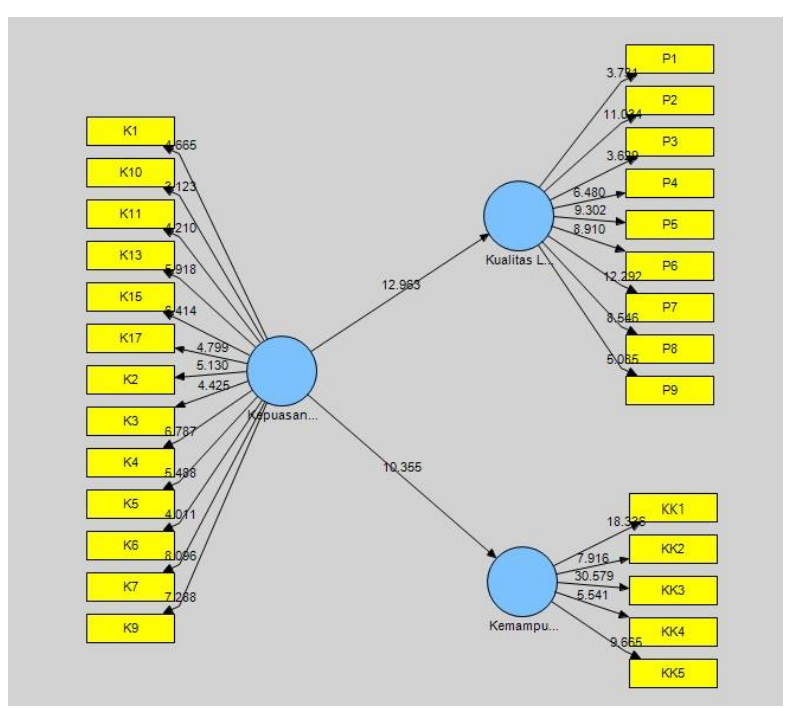

Gambar 4. Hasil Bootstapping (Olahan SmartPLS 2.0)

Penilaian dan pengujian hasil dari perhitungan bootsrapping pada SmartPLS 2.0 adalah sebagai berikut:

a. Nilai Signifikasi Masing-masing Indikator

Diperoleh dari hasil perhitungan t-statistik pada masing-masing indikator pada kelompok masing-masing variabel latennya dengan ketentuan dianggap indikator tersebut signifikan jika nilai t-statistiknya > 1.96 (pada alfa $5 \%)$. Hasilnya sebagai berikut:

b. Nilai Signifikasi Masing-masing Indikator

Berdasarkan hasil olahan data, menunjukkan semua indikator-indikator memiliki nilai tstatistiknya > 1.96, yang berarti bahwa semua indikator tersebut mempunyai nilai yang signifikan. Nilai terbesar pada komponen KK3 yaitu “pengurus bersungguh-sungguh 
dalam memberikan pelayanan”. Berikutnya adalah KKI "pengurus mampu memberikan informasi pelayanan dengan jelas sesuai prosedur" dan yang ketiga P2 "pengurus bersikap disiplin dalam memberikan layanan"

\section{c. Nilai Signifikansi Hubungan Antar Variabel Laten}

Path Coefficients dapat dilihat bahwa tiga parameter jalur hubungan yang menjadi hipotesa pada penelitian ini bernilai t-statistiknya > 1.96 yang menunjukkan signifikansi pengaruh antar variabel laten sebagai berikut:

I. Kepuasan Mahasiswa berpengaruh signifikan terhadap Kualitas Layanan Berdasarkan Berdasarkan tabel 8, nilai t-statistik pengaruh Brand UT terhadap Harga sebesar 12.962623 , nilai ini lebih besar dari nilai t-tabel I,98 untuk level signifikan 0.05 (5\%).

2. Kepuasan Mahasiswa berpengaruh signifikan terhadap Kemampuan Kerja. Berdasarkan Berdasarkan tabel 9, nilai t-statistik pengaruh Brand UT terhadap Loyalitas sebesar 10.354608, nilai ini lebih besar dari nilai t-tabel I,98 untuk level signifikan 0.05 (5\%).

Pengujian terhadap inner model dilakukan dengan melihat nilai R-square yang merupakan uji goodness-fit model sebagai berikut: R-square menunjukan nilai untuk varibel laten Kualitas Layanan didapatkan nilai sebesar 0.479359. Hal ini menunjukan bahwa variabel laten Kepuasan Mahasiswa berpengaruh sebesar 47.93\% terhadap Kualitas Layanan. Untuk variabel laten Kemampuan Kerja berpengaruh terhadap Kepuasan Mahasiswa sebesar 40,96\%.

Dari temuan penelitian, pengurus pokjar mempunyai keterampilan dan mampu dalam melayani mahasiswa dan calon mahasiswa. Dari sisi kepuasan mahasiswa terhadap layanan yang tidak dilayani oleh UPBJJ-UT mampu dilayani oleh mitra UT yaitu pengurus pokjar yang berada di kota kabupaten yang dipengaruhi oleh faktor kredibilitas, empati dan daya tanggap. Hal ini dapat dipengaruhi dari tingkat pengalaman dari pengurus pokjar. Hasil penelitian ini mendukung penelitian sebelumnya dari Susila (2010) bahwa supporting sistem diharapkan selalu meningkatkan pelayanan pada masyarakat pengguna sehingga kepuasan semakin meningkat.

Daya jangkau layanan yang diberikan pengurus pokjar dalam memberikan layanan registrasi, pengurusan tutorial, layanan ujian serta layanan sosialisasi promosi di UPBJJ-UT Palangka Raya dan berdampak sehingga mahasiswa merasa puas dengan layanan yang diberikan oleh pengurus pokjar. Skala pelayanan kadang tidak sebanding dengan jumlah sumber daya pengurusnya akan tetapi optimalisasi pelayanan tetap meningkat signifikan. Dari sisi keefektifan dari Kinerja pengurus pokjar terhadap implementasi dari standar sesuai dengan prosedur disesuaikan dengan sarana dan prasarana yang dimiliki pokjar.

\section{KESIMPULAN}

Hasil penelitian ini menunjukkan bahwa kualitas layanan pengusur pokjar baik, kompetensi yang memenuhi dan kinerja layanan baik; serta mahasiswa puas terhadap layanan pengurus pokjar. Layanan yang diberikan Pengurus Pokjar harus ditunjang dengan kecakapan dari pengurusnya dan perbandingan antara SDM dengan jumlah mahasiswa yang dilayani. Peningkatan Sarana dan prasaran harus didukung oleh UPBJJ-UT, karena selama ini pokjar tidak diberikan sarana dan prasarana penunjang layanan kepada mahasiswa. Pengurus pokjar menyediakan modal pribadi untuk mendukung pelayanan kepada calon mahasiswa dan mahasiswa yang tidak dapat datang ke UPBJJ-UT.

\section{UCAPAN TERIMA KASIH}

Peneliti mengucapkan terima kasih kepada Universitas Terbuka yang telah memberikan dana penelitian 
penleitian mula tahun 2017 sehingga penelitian ini dapat terlaksana.

\section{REFERENSI}

Boulter, N., M. Dalziel., dan J. Hill. 1996. People and Competencies, London: Bidlles, Ltd

Dharma, Surya. 2004. Manajemen Kinerja, Falsafah, Teori dan Penerapannya. Pustaka Pelajar: Yogyakarta.

llyas Yaslis. 2005. Kinerja, Teori dan Penelitian. Liberty: Yogyakarta.

Kotler, Philip. 1994. Manajemen Pemasaran Jilid I, Edisi Keenam. Jakarta: Erlangga.

Kotler, P \& Keller, Kevin L. 2007. Manajemen Pemasaran. Jilid I, Edisi I2. P.T. Indeks Kelompok Gramedia. Jakarta.

Lovelock, CH. 1988. Managing service. New Jersey: Prentice Hall.

Liao, RenChieh. 20II. Combining ISO 900I QMS and PZB Model to Reach Customer Satisfaction for School's Extension Education Organization -- An Integrated Approach and Empirical Study in Taiwan. International Journal of Digital Content Technology and its Applications 5(6):207-2I3.

Mangkunegara, Anwar Prabu. 2005. Manajemen Sumber Daya Manusia Perusahaan, Cetakan keenam. Remaja Rosda Karya: Bandung.

Parasuraman, A., Zeithaml, V.A.,\& Berry, L.L. 2007., Reassessment of Expectations as a Comparison Standard in Measuring Service Quality: Implications for Future Research Journal of Marketing.

Rangkuti, Freddy. 2003. Teknik Mengukur Dan Strategi Meningkatkan Kepuasan Pelanggan Dan Analisis Kasus PLN-JP. Jakarta: PT Gramedia Pustaka Utama

Rivai, Veithzal. 2005. Manajemen Sumber Daya Manusia Untuk Perusahaan, Dari Teori Ke Praktek. PT. Rajagrafindo Persada: Jakarta.

Simamora, Hendry. 2004. Manajemen Sumber Daya Manusia. STIE.YKPN: Jogjakarta.

Susila, Linda Nur. 20I0. Analisis Kualitas Pengaruh Pelayanan Kantor Kelurahan Terhadap
Kepuasan Masyarakat Kelurahan Jagalan Kecamatan Jebres Kota Surakarta. Journal of Rural and Development Volume I No. I Februari 2010

Universitas Terbuka, 2018. Pedoman Pengurus Kelompok Belajar Mahasiswa Universitas Terbuka. Universitas Terbuka: Tangerang Selatan.

Yarimoglu, Emel Kursunluoglu 20I5. A Review of Service and E-Service Quality Measurements: Previous Literature and Extension : Journal of Economic and Social Studies 5.I Spring 2015 : 169-200

Zeithaml, V.A. 1993. The Nature and Determinants of Customer Expectations of Service. Journal of Academy of Marketing Science, Vol. 21, No. I, pp. I-I 2. 